\title{
"Tacitus Trap" and the Transcendence of Traditional Wushu Cultural Image: Other Shaping, Self-shaping and Information Dissemination
}

\author{
Zhangkun ${ }^{1, a}$ \\ ${ }^{1}$ Author unit: Sports Department of Nanjing vocational college of science and technology \\ ${ }^{a}$ Corresponding author. Email: $565976790 @ q q . c o m$
}

\begin{abstract}
With the accumulation of negative information of traditional Wushu, the cultural image of traditional Wushu began to fall to the bottom of the contempt chain, and then formed the identity crisis of the cultural image of traditional Wushu. In this reality, traditional Wushu, whether vocal or silent, cannot win the trust of the public, so as to enter the "Tacitus trap" and affect the current and future development of traditional Wushu. Therefore, how can traditional Wushu go out of the abnormal road from excessive praise to excessive derogation, adhere to the position of the return of traditional Wushu, and build a Wushu destiny community that needs to actively voice and cooperate with scholars, government and people, so as to reshape the cultural image of traditional Wushu and form a coordinated development pattern of Competitive Wushu, traditional Wushu and healthy Wushu.
\end{abstract}

Keywords: Traditional Wushu, contempt chain, cultural image, Tacitus trap, Information dissemination.

\section{PREFACE}

Traditional Wushu is not only one of the carriers of Chinese traditional culture, but also a cultural symbol with the highest degree of international cognition of Chinese culture. It plays an important role in the process of foreign cultural exchange. Among them, cultural image is an important cultural capital of traditional Wushu culture ). Scholars Dan Nimmo and R.L. savage believe that image is people's "cognition and attitude towards the construction of target things, things or others" [1]. According to this definition, the construction of cultural image is inseparable from the cultural interaction between communicators and audiences. However, the audience of traditional Wushu culture, especially those in heterogeneous cultural background, except a few traditional Wushu cultural elites, do not have frequent contact and in-depth understanding of traditional Wushu, so the audience will tend to "use his mind to observe the world he has never seen, touched, smelled, heard and thought about.[2] He will gradually create in his mind a reliable image of the world beyond his sight. This change has not only directly led to the "crisis that Chinese Traditional Wushu must face the collapse of the overall image", but also "has directly affected the survival and development of traditional Wushu at present and in the future for a long time.

\section{DISDAIN CHAIN: THE EXISTENCE MODE AND CHANGE OF TRADITIONAL WUSHU CULTURAL IMAGE}

This paper summarizes the change process of traditional Wushu cultural image from "admiration" to "contempt" as the phenomenon of "contempt chain" in Wushu cultural ecosystem "The word "despise chain" was first seen in the special topic of "City Weekly" of Shenzhen magazine of Southern Metropolis Daily on April 7, 2012, which means a phenomenon of feeling good and looking down on others. Because the word "despise chain" has the elements of joking and belittling each other, we can not only see the mentality of self-satisfaction and good self-feeling in the martial arts ecosystem, as well as the intensification of discord and differentiation within the martial arts ecosystem, but also fully perceive the existence mode of traditional martial arts cultural image and the general mirror image of change. 


\subsection{Hierarchical model of Wushu contempt chain}

With the deepening of the transformation process of Wushu modernization, the fission phenomenon of traditional Wushu has appeared. Traditional Wushu is divided into different sports forms in a series of binary pairs, such as tradition and modernity, transformation and return, health preservation and competition, official and folk. Both traditional Wushu and competitive Wushu have "too much self-confidence and too little self-blame"; the mentality of "condemning others too much and investigating yourself too little", so as to despise different types of Wushu cultural forms instead of seeking interaction, understanding and reference, which constitutes a "despise chain" Wushu cultural ecological environment. [3]

\subsection{Mutual tearing mode of Wushu disdain chain}

In fact, the contempt chain of cultural image has not been recognized by traditional Wushu and competitive Wushu for a long time. Traditional Wushu and competitive Wushu are born from the same root, and the contempt for cultural image is naturally the most direct. Traditional Wushu is deeply resentful of the times when it has been repeatedly split and dismembered. In particular, after Sanda returned to the public's vision, it quickly parted ways with traditional Wushu, which has triggered the disgust and contempt of traditional Wushu for Competitive Wushu to a certain extent.[4]

\section{TACITUS TRAP: A NEW DILEMMA BROUGHT BY THE IMAGE IDENTITY CRISIS OF TRADITIONAL WUSHU CULTURE}

\subsection{Interpretation of the concept of "Tacitus trap"}

The so-called "Tacitus trap" originated from a law proposed by the ancient Roman historian Publius Cornelius Tacitus (ca. A.D. 55-120), It means that "when the public power loses its credibility, the society will give a negative evaluation no matter what speech or doing".

\section{2."Tacitus trap" of traditional Wushu cultural image}

At present, the credibility of the cultural image of traditional Wushu has been seriously damaged. Traditional Wushu has been suspected and ridiculed as flower boxing and embroidered legs, abandoned as my shoes, and even thought that "unable to fight" is the only political correctness. The kung fu legend of traditional
Wushu in history was written off by Hong Kong media reporters, and traditional Wushu also suffered repeated blows from language violence from all sides. In fact, although the traditional Wushu is joked arbitrarily, the culture represented by the traditional Wushu is really Ko.

\subsection{The new dilemma of traditional Wushu under the "Tacitus trap"}

\subsubsection{Cultural and psychological dilemma of traditional Wushu}

The "Tacitus trap" has the characteristics of habitual imputation, collective opinions and stereotyped attitude, which makes the traditional Wushu have a new dilemma. One of the difficulties is the further change of the image and cultural orientation of traditional Wushu in the contempt chain, which weakens the cultural charm of traditional Wushu, makes the public move from cultural self-confidence to cultural inferiority, and loses confidence in traditional Wushu culture.

\subsubsection{Inheritance dilemma of traditional Wushu}

As a former professional skill, traditional Wushu has long lost its original survival soil. Therefore, how to inherit traditional Wushu is a major topic put forward by history. In this regard, traditional Wushu has not been able to better solve the relationship between aesthetics and fighting for a long time. Therefore, in the face of the doubt of public traditional Wushu, traditional Wushu is in a situation where there is no argument, resulting in the dilemma of traditional Wushu inheritance.[5]

\subsubsection{International communication dilemma of traditional Wushu}

The cultural image of traditional Wushu has become a Tacitus trap, which will not only bring the problem of "family confusion", but also bring the new dilemma of "outsiders' misunderstanding". With the increase and accumulation of external doubts about Traditional Wushu, it will directly lead to the decline of the communication power of traditional Wushu, and then transmitted to the cross-cultural communication of Wushu as a whole.

\section{OTHER SHAPING: THE ATTRIBUTION OF THE CHANGE OF TRADITIONAL WUSHU CULTURAL IMAGE IDENTITY}

\subsection{From profession to Witchcraft: the "abandonment" of traditional Wushu in the late Qing Dynasty}

In the long development history, Wushu has been in 
the state of military vocational skills and market vocational skills (hanging sub line, divided into "support, pull, poke, point, sharp, fishy", etc.) for a long time. It is generally spread among low-level people in society. However, at the end of the Qing Dynasty, whether as a military career or a marketplace career, traditional Wushu encountered an unprecedented survival crisis. Obviously, there was no "cultural image" of traditional Wushu at that time. Moreover, because traditional Wushu was mixed with witchcraft, superstition and metaphysics in the boxing ceremony, that is, through "grafting martial arts moves and witchcraft ceremony and stimulating the crazy state of collective combat with the help of the confluence of witchcraft and martial Arts", the cultural image of traditional Wushu fell sharply for the first time. Therefore, traditional Wushu has been ignored and ridiculed and tends to be silent. This situation even continued to the new cultural movement period when traditional Wushu began its modernization transformation.[6]

\subsection{From grassroots to temples: the "borrowing" of traditional Wushu in the period of the Republic of China}

In the early period of the Republic of China, the traditional Wushu, which was originally a grass-roots profession, gradually began to change from the state of "mainly spreading and learning in rural areas and living and dying" to temple culture. With the spread of Western learning to the East, western sports culture also has a great impact on the original value cognition system. China's traditional sports culture system is bound to directly face the strong hedge of western culture, which will lead to some people's discomfort and even panic. At the beginning of the 20th century, in the critical period of national survival, traditional Wushu has become an effective way to realize the national will of "invigorating the national spirit and casting the martial people" and "strengthening the country and species". Therefore, traditional Wushu has been highly valued and borrowed by the government.[7]

\subsection{From sports to heritage: the "function" of traditional Wushu since the founding of new China}

In the early days of the founding of the people's Republic of China, in order to quickly get rid of poverty and backwardness, China started the modernization process of various undertakings. During the period of the Republic of China, the transformation of Wushu modernization interrupted by war was continued to operate under the framework of socialist sports. After the reform and opening up, the role of traditional culture such as diet, art and martial arts in the construction and dissemination of national image began to show.
Obviously, cultural Wushu is more conducive to the shaping and dissemination of national image than Sports Wushu, so traditional Wushu began to appear in the image of cultural heritage.

\subsection{Summary}

To sum up, the cultural image of traditional Wushu has gone through the shaping process of "feudal Wushu", "Sports Wushu" and "cultural Wushu". In essence, it is the otherness of the self-worth of traditional Wushu. In other words, traditional Wushu is basically in the position of others in this shaping process" "He plastic" borrows the concept of communication as "an external evaluation and recognition", and "he plastic" is a construction method derived from the feelings and will of others ". Obviously, the result of other shaping of traditional Wushu will inevitably lead to the fact that the cultural image of Wushu, whether despised or respected, comes from the outside.Building a community of self-shaping and co shaping destiny: the transcendental path of the cultural image of traditional Wushu.

\section{BUILDING A COMMUNITY OF SELF SHAPING AND CO SHAPING DESTINY: THE TRANSCENDENTAL PATH OF THE CULTURAL IMAGE OF TRADITIONAL WUSHU}

\subsection{Self plastic}

\subsection{1.let the tradition speak for itself: constructing the discourse system of traditional Wushu}

Self-shaping, because "Wushu has its own path and history", and adheres to "based on its own laws and foundation". The lack of discourse power and sideline make traditional Wushu shaped into a "lonely and silent other" by the mainstream culture, which is also the inevitable result of cultural aphasia and unable to participate in the formulation of game rules for a long time. The theoretical basis for reshaping the cultural image of traditional Wushu lies in that the basic characteristic of culture is change, that is, culture is plastic. However, the image shaping of traditional Wushu cultural heritage is not conducive to the inheritance and development of traditional Wushu. Because once it is shaped into a cultural heritage, it means that traditional Wushu does not need to evolve or communicate with the outside world, but only needs to be preserved intact. 


\subsubsection{Restoring cultural reality: rebuilding the practice system of traditional Wushu}

Although the value orientation of traditional Wushu has changed from fighting to fitness, fighting is still an important cultural feature and logo of traditional Wushu, because traditional Wushu is not only "the behavior set and activity style formed by traditional Chinese people in dealing with physical conflicts", but also "full of life wisdom accumulated by Chinese people from generation to generation to deal with the environment "Survival skills and life cultivation" to highlight its unique cultural orientation. In the diversified era, traditional Wushu should take the initiative to change, transform the military actual combat of traditional Wushu into the actual combat fighting technology in the challenge arena, and rebuild its own practice system..[8]

\subsection{Plastic combination}

\subsubsection{Scholars speak}

The form of combining with scholars is an important strategy for the reconstruction of traditional Wushu cultural image, and one of the main links is the way of endorsement by scholars. Generally speaking, scholars can speak on a higher platform through academic language, so as to avoid the "Absence" of traditional Wushu discourse, and avoid the occurrence of too much randomness, lack of scientificity, and even being influenced by "feelings" when formulating traditional Wushu development policies.[9]

\subsubsection{Support of competent department}

There is no doubt that Wushu management department determines the development trend of Wushu to a great extent. From the perspective of Institutional Interpretation path, the development of Wushu relies on institutionalization to make continuous achievements, although it inevitably falls into path dependence. Generally speaking, the institutionalized development path of Wushu will be affected by external conditions, so it will give Wushu different missions in different historical periods.

\subsubsection{Folk response}

Traditional Wushu is a grass-roots culture rooted in the folk, and it is also the basic soil for the inheritance and dissemination of traditional Wushu. In other words, Chinese Traditional Wushu comes from the people, and the important way to develop and excavate is the people. Therefore, the folk power is an important support for the reconstruction of the cultural image of traditional Wushu.

\subsubsection{Summary}

The advantage of traditional Wushu lies in culture, which not only carries the traditional Chinese philosophy, but also embodies the spirit of Chinese traditional culture. Therefore, rich culture is also an important resource for traditional Wushu to reshape its cultural image.In this regard, Folk Wushu groups should actively respond to the reconstruction of the cultural image of traditional Wushu, which can not only promote the modernization transformation of traditional Wushu, but also help traditional Wushu to complete its own micro innovation under a certain macro background..

\section{THE DILEMMA OF INTERNATIONAL COMMUNICATION OF TRADITIONAL WUSHU}

The cultural image of traditional Wushu has become a Tacitus trap, which will not only bring the problem of "family confusion", but also bring the new dilemma of "outsiders' misunderstanding". With the increase and accumulation of external doubts about Traditional Wushu, it will directly lead to the decline of the communication power of traditional Wushu, and then transmitted to the cross-cultural communication of Wushu as a whole.

As one of the important elements of the international communication of Chinese traditional culture, traditional Wushu vividly interprets the characteristics of Chinese traditional culture with its special charming sports language. In essence, "the worldwide dissemination of culture is not a curiosity hobby, but the recognition of the internal spirit and basic value of a culture". However, as far as traditional Wushu is concerned, the internal spirit and basic value of traditional Wushu, the local cultural area has encountered the largest and deepest doubt in history among the local cultural public, and the views of all parties are also debating and unable to agree. All these add new obstacles to the international dissemination of traditional Wushu.

\section{CONCLUSION}

In summary, the traditional martial arts culture image has gone through the process of "feudal martial arts", "sports martial arts" and "cultural martial arts" . In essence, it is the otherness of traditional Wushu's self-value. That is to say, the traditional martial arts in this shaping process is basically in the state of others shaping. "He su" is borrowed from the concept of communication, as "a foreign evaluation and recognition", he su "is a kind of feelings and will from others to build a method". It is obvious that the result of his shaping of traditional martial arts will inevitably lead to the cultural image of martial arts, whether it is despised or respected from the outside. That is to say, 
what kind of martial arts is needed by the outside society, then martial arts will be made and described as what is needed, which is also the historical and realistic cause of the formation of the culture ecology of the martial arts disdain chain. In other words, traditional martial arts lost the right to speak in the cultural shaping, so the image of traditional martial arts culture was finally brought into the "contempt chain" of cultural ecology step by step. Then, the traditional Wushu Culture image how to break the contempt chain of the ecological model, return to the normal cultural image, this topic proposed to build a self-shaping and co-shaping of the fate of the community.

\section{REFERENCES}

[1] DAN NIMMO \&R. L. SAVAGE. Candidates and Their Images: Concepts, Methods and Findings, Pacific Palisades: Goodyear,1976.

[2] Li Yuan, Liang Qinchao, Jiang Nan. "Playing" and "not playing": binary cognition of Wushu image [J]. Journal of Beijing University of physical education, 2018,41 (7): 127

[3] [US] Walter Lippmann. Public opinion [M]. Shanghai: Shanghai People's publishing house, 2006:21

[4] Li Yan, Wang Gang. Chinese Wushu: from glory to embarrassment [J]. Journal of Wuhan Institute of physical education, 2015, 49 (4): 49-55

[5] Ma Lianzhen. The value system of traditional Wushu needs to be reconstructed urgently -- some thoughts triggered by $\mathrm{Xu}$ Xiaodong event [J]. Journal of physical education, 2018,25 (5): 25

[6] Lu Xiaohei, Wang Gang, Zhu Damei. Learning from experience: the lack of contemporary Chinese Wushu Development [J]. Journal of Nanjing Institute of physical education, 2009,23 (1): 22

[7] Yang Jianying. Comparative study of traditional Wushu and modern competitive Wushu [J]. Journal of Tianjin Institute of physical education, 2014,19 (3): 93

[8] Wang Guozhi, Qiu Pixiang. The crux and development strategy of "the more martial arts, the more lonely" of Chinese Wushu [J]. Journal of Wuhan Institute of physical education, 2010,44 (4): 91

[9] Shen Guoqing. From Wulin conference to wma -the contemporary return and agitation of the development of Chinese Wushu [J]. Journal of Wuhan Institute of physical education, 2011,45 (2): 30 